\title{
Reduced expression of chemerin is associated with poor clinical outcome in acute myeloid leukemia
}

\author{
Jing Zhang ${ }^{1,2}$, Jiao Zhou ${ }^{1,2}$, Xi Tang ${ }^{1,2}$, Ling-Yu Zhou ${ }^{1,2}$, Ling-Ling Zhai, ${ }^{1,2}$ Minse \\ Evola-Deniz Vanessa ${ }^{1}$, Jing Yi ${ }^{1,2}$, Yun-Yun $\mathbf{Y i}^{1,2}$, Jiang Lin ${ }^{1}$, Jun Qian ${ }^{2}$ and Zhao- \\ Qun Deng ${ }^{1}$ \\ ${ }^{1}$ Department of Laboratory Center, The Affiliated People's Hospital of Jiangsu University, Zhenjiang, 212002, Jiangsu, People's \\ Republic of China \\ ${ }^{2}$ Department of Hematology, The Affiliated People's Hospital of Jiangsu University, Zhenjiang, 212002, Jiangsu, People's \\ Republic of China \\ Correspondence to: Zhao-Qun Deng, email: zqdeng2002@163.com \\ Jiang Lin, email: linjiangmail@sina.com \\ Keywords: chemerin, diagnosis, prognosis, acute myeloid leukemia, biomarker \\ Received: August 01, $2017 \quad$ Accepted: August 29, $2017 \quad$ Published: September 30, 2017 \\ Copyright: Zhang et al. This is an open-access article distributed under the terms of the Creative Commons Attribution License 3.0 \\ (CC BY 3.0), which permits unrestricted use, distribution, and reproduction in any medium, provided the original author and source \\ are credited.
}

\section{ABSTRACT}

Chemerin is dysregulation in numerous solid cancers. However, only little is known about the role of chemerin in acute myeloid leukemia (AML). In this study, we aimed to investigate the expression and clinical significance of recently described chemerin in acute myeloid leukemia ( $A M L)$. The expression of chemerin in 149 patients with de novo AML and 35 normal controls was quantified by Real-time quantitative PCR (RQ-PCR). Chemerin was down-expressed in AML compared with controls $(P=\mathbf{0 . 0 4 2})$. A receiver operating characteristic (ROC) curve revealed that chemerin expression could differentiate patients with AML from control subjects (AUC $=0.611,95 \% \mathrm{CI}$ : $0.490-0.732 ; P=0.042$ ) respectively. The cohort of $A M L$ patients was divided into two groups according to the cut-off value of 0.0826 ( $79 \%$ sensitivity and $54 \%$ specificity, respectively). In addition, the AML patients with low chemerin expression had significantly shorter overall survival (OS) than those with high chemerin expression $(P=0.049)$. Moreover, multivariate survival analysis confirmed that chemerin was an independent prognostic factor for AML patients. In conclusion, downregulation of chemerin might be a useful diagnostic and prognostic factor for AML patients.

\section{INTRODUCTION}

Acute myeloid leukemia (AML), the most common type of adult leukemia, is characterized by the accumulation of cloning and differentiation arrest in the bone marrow and blood. It is easy to cause fatal infection, bleeding, or organ infiltration [1]. Acute myeloid leukemia with myelodysplasia-related changes is identified by brief morphologic, cytogenetic and clinical features, patients with this disease still have significant heterogeneity in clinical behavior and response to treatment [2-5].

Chemerin (RARRES2 [retinoic acid receptor responder 2] and TIG2 [tazarotene induced gene 2])
[6], is purified from the ascetic fluids of ovarian cancer patients and has been shown to be a natural ligand for G protein-coupled receptor-1 (GPR-1) and chemokine C-C motif receptor-like-2 (CCRL-2) [7, 8]. Certainly, the role of chemerin as a chemoattractant is to promote the recruitment of these cells into sites of tissue injury and lymphoid organs $[9,10]$. Chemerin is found to be highly expressed in a variety of tissues, such as adipose tissue, liver, pancreas, skin, etc, which regulates the function of innate immune cells [11, 12]. Growing evidence suggests that chemerin might also have a role in cancer development. Some studies have revealed that the expression of chemerin is different in some types of 
cancers. Chemerin expression was significantly decreased in hepatocellular carcinoma (HCC) [13], skin squamous cell carcinoma [14], melanoma [15] compared with normal and/or benign tumors in each organ. Conversely, another study showed that the expression of chemerin was overexpressed in colorectal cancer [16], squamous cell carcinoma of the oral tongue [17], gastric cancer [18] correlated with tumor angiogenesis and poor clinical outcomes of patients and upregulatedin grade III/IV glioma tissues compared with grade II ones or brain samples from patients with epilepsy [19]. Nevertheless, these surveys demonstrate that the dysregulation of chemerin may have an important impact on tumorigenesis and progression, but the expression and roles of chemerin in AML remain unclear.

In this study, we aimed to investigate chemerin expression levels and its predictive role in de novo AML patients, and explored its relationship with clinical parameters. It could provide clinical diagnostic and prognostic biomarker for AML.

\section{RESULTS}

\section{Chemerin expression in normal controls and AML patients}

We detected the level of chemerin expression in AML and normol controls. As shown in Figure 1, the levels of chemerin were significantly decreased in AML patients (0.0000-1.3786, median 0.0151) compared with healthy controls (0.0000-88.5733, median 0.0855, $\mathrm{P}=0.042)$.

\section{Differentiating capacity of chemerin expression}

To assess the performance of chemerin expression as a marker, ROC curves were constructed to analyze the sensitivity of this marker in distinguishing AML patients from healthy controls. (AUC $=0.611,95 \% \mathrm{CI}$ : 0.490 $0.732, \mathrm{P}=0.042$, Figure 2 ). With a cut-off value of 0.0826 , the sensitivity and the specificity were $79 \%$ and $54 \%$, respectively. These results demonstrated that chemerin expression might serve as a valuable biomarker for AML diagnosis.

\section{$P=0.042$}

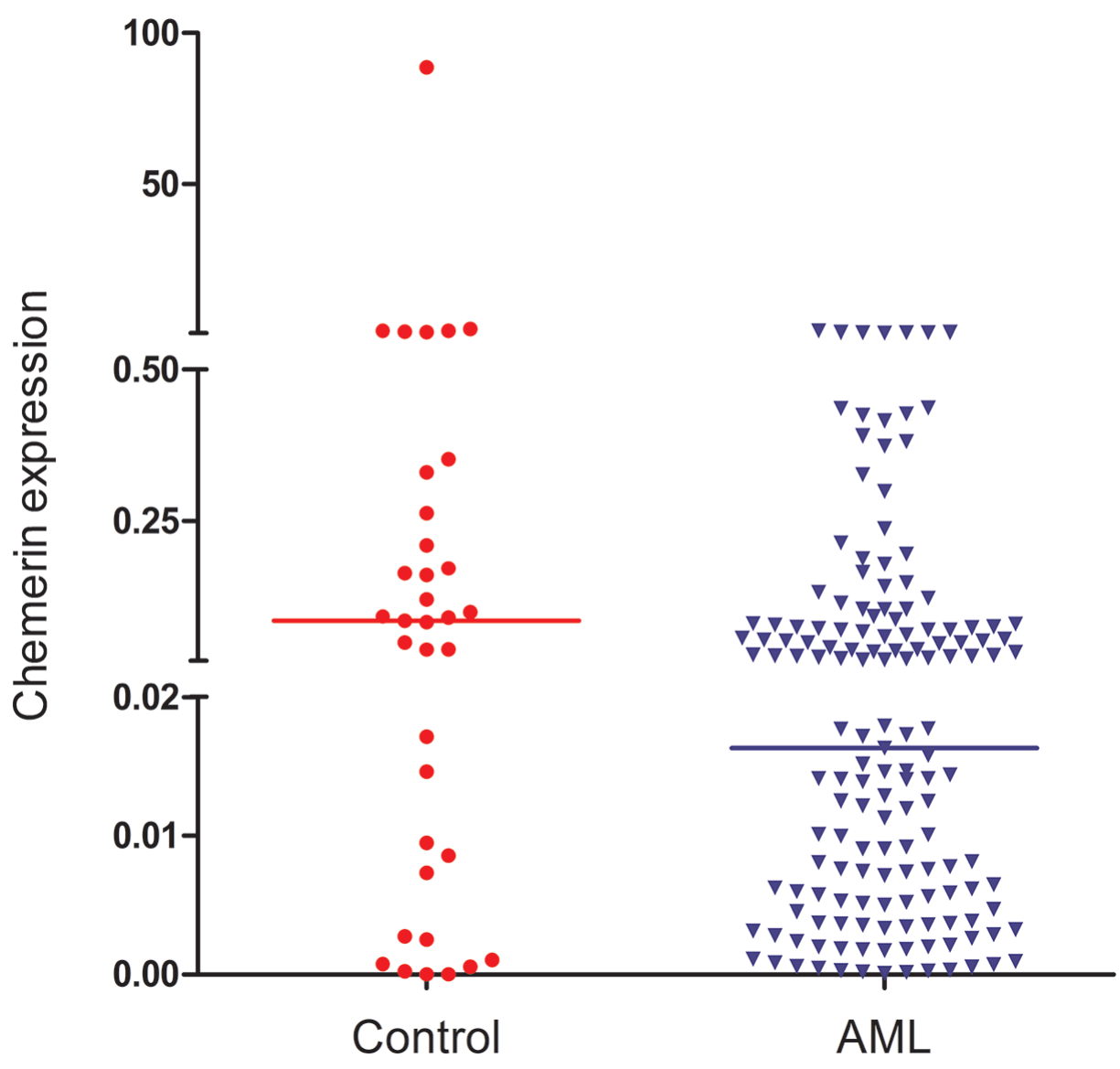

Figure 1: Relative expression levels of chemerin in AML patients and controls. 


\section{Clinical and laboratory characteristics of AML patients}

To assess the prognostic significance of chemerin expression levels, we used chemerin expression cutoff value 0.0826 as a threshold for dividing 149 AML patients into two groups, high chemerin expression group $(\geq 0.0826)$ and low chemerin expression group $(<0.0826)$. There were no significant differences in age, white blood cells (WBC), hemoglobin (HB), platelets (PLT), and ten gene mutations (DNMT3A, U2AF1, IDH1/2, N/K-RAS, C/EBPA, NPM1 and c-KIT) between chemerin lowexpressed group and high-expressed group $(\mathrm{P}>0.05$, Table 1). Moreover, we did not observe significant differences in BM blasts, FAB classifications, and karyotypes (Table 1).

\section{Association between chemerin expression and clinical outcome}

Among 149 cases, 140 patients with available follow-up data were eligible for the complete remission (CR) analysis and 9 patients were excluded because of incomplete follow-up. High-expressed patients had no significantly $\mathrm{CR}$ rate compared with low-expressed patients in whole AML, however, there was a trend of high chemerin expression toward higher $\mathrm{CR}$ after induction therapy $(57 \%$ vs $41 \%, \mathrm{P}=0.063$, Table 1$)$. Kaplan-Meier analysis results showed that patients with low chemerin expression had poorer overall survival (OS) than those with high chemerin expression in whole AML patients (median 5.5 vs 16.5 months, respectively, $\mathrm{P}=0.049$, Figure 3). Multivariate

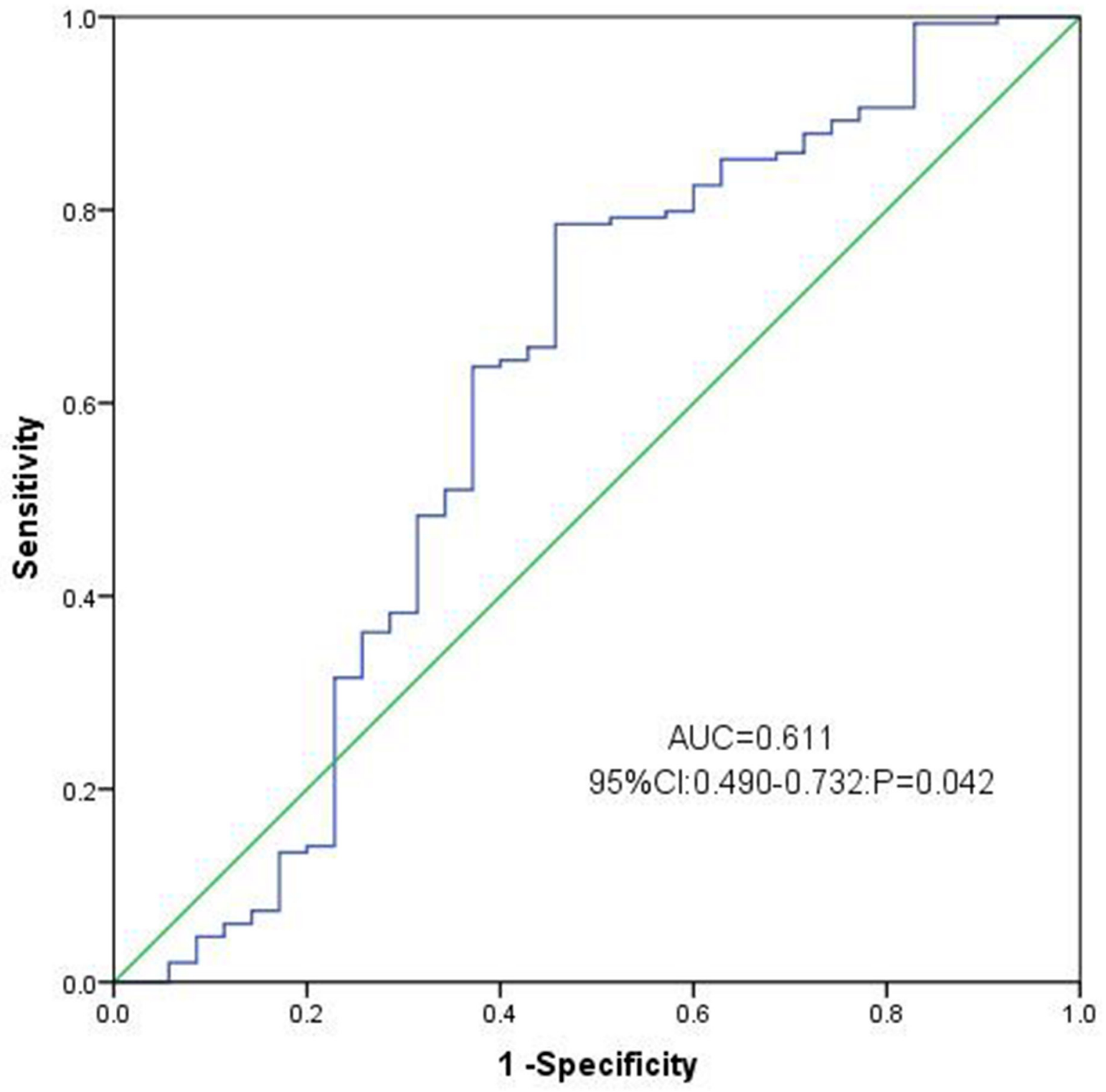

Figure 2: ROC curve analysis using Chemerin for discriminating AML patients from controls. 
Table 1: Comparison of clinical manifestations and laboratory features between AML patients with low and high expression

\begin{tabular}{|c|c|c|c|}
\hline Patient's parameters & High $(n=32)$ & Low (n=117) & $P$ value \\
\hline Sex, male/female & $20 / 12$ & $68 / 49$ & 0.690 \\
\hline Median age, years (range) & $56.5(21-80)$ & $56(10-93)$ & 0.633 \\
\hline $\begin{array}{l}\text { Median WBC, } \times 10^{9} / \mathrm{L} \\
\text { (range) }\end{array}$ & $9.3(0.3-154.0)$ & $15.4(4.0-528.0)$ & 0.424 \\
\hline $\begin{array}{l}\text { Median hemoglobin, g/L } \\
\text { (range) }\end{array}$ & $75.0(32-120)$ & $78.0(41-138)$ & 0.118 \\
\hline $\begin{array}{l}\text { Median platelets, } \times 10^{9} / \mathrm{L} \\
\text { (range) }\end{array}$ & $33.0(4-415)$ & $40.0(3-447)$ & 0.536 \\
\hline BM blasts, \% (range) & $39.0(1-99)$ & $49.25(3-97.5)$ & 0.567 \\
\hline CR (-/+) & $13 / 17$ & $69 / 41$ & 0.063 \\
\hline FAB & & & 0.227 \\
\hline M0 & $1(3 \%)$ & $2(2 \%)$ & \\
\hline M1 & $1(3 \%)$ & $6(6 \%)$ & \\
\hline M2 & $12(38 \%)$ & $43(37 \%)$ & \\
\hline M3 & $8(25 \%)$ & $23(19 \%)$ & \\
\hline M4 & $6(19 \%)$ & $25(21 \%)$ & \\
\hline M5 & $1(3 \%)$ & $16(13 \%)$ & \\
\hline M6 & $3(9 \%)$ & $2(2 \%)$ & \\
\hline Karyotype classification & & & 0.615 \\
\hline Favorable & $11(34 \%)$ & $31(26 \%)$ & \\
\hline Intermediate & $18(57 \%)$ & $67(57 \%)$ & \\
\hline Poor & $2(6 \%)$ & $16(14 \%)$ & \\
\hline No data & $1(3 \%)$ & $3(3 \%)$ & \\
\hline Karyotype & & & 0.924 \\
\hline normal & $15(48 \%)$ & $48(41 \%)$ & \\
\hline $\mathrm{t}(8 ; 21)$ & $3(9 \%)$ & $6(5 \%)$ & \\
\hline $\mathrm{t}(16 ; 16)$ & $0(0 \%)$ & $1(1 \%)$ & \\
\hline $\mathrm{t}(15 ; 17)$ & $8(25 \%)$ & $22(18 \%)$ & \\
\hline+8 & $0(0 \%)$ & $5(4 \%)$ & \\
\hline$-5 / 5 q-$ & $0(0 \%)$ & $3(3 \%)$ & \\
\hline$-7 / 7 q-$ & $0(0 \%)$ & $1(1 \%)$ & \\
\hline $\mathrm{t}(9 ; 22)$ & $0(0 \%)$ & $1(1 \%)$ & \\
\hline others & $3(9 \%)$ & $14(12 \%)$ & \\
\hline complex & $2(6 \%)$ & $13(11 \%)$ & \\
\hline No data & $1(3 \%)$ & $3(3 \%)$ & \\
\hline \multicolumn{4}{|l|}{ Gene mutation* } \\
\hline$C E B P A(+/-)$ & $4 / 23$ & $12 / 88$ & 0.745 \\
\hline \multirow[t]{2}{*}{ NPM1 (+/-) } & $4 / 23$ & $11 / 89$ & 0.523 \\
\hline & & & (Continued) \\
\hline
\end{tabular}




\begin{tabular}{lccc}
\hline Patient's parameters & High $(\mathbf{n}=\mathbf{3 2})$ & Low $(\mathbf{n = 1 1 7})$ & P value \\
\hline FLT3-ITD (+/-) & $4 / 23$ & $12 / 88$ & 0.745 \\
$c-K I T(+/-)$ & $0 / 27$ & $4 / 96$ & 0.578 \\
$N / K-R A S(+/-)$ & $0 / 27$ & $8 / 92$ & 0.201 \\
$I D H 1 / 2(+/-)$ & $0 / 27$ & $2 / 98$ & 1.000 \\
$D N M T 3 A(+/-)$ & $2 / 25$ & $7 / 93$ & 1.000 \\
$U 2 A F 1(+/-)$ & $2 / 50$ & $3 / 47$ & 0.287 \\
\hline
\end{tabular}

WBC, white blood cells; FAB, French-American-British classification; AML, acute myeloid leukaemia; CR, complete remission; ; , percentage was equal to the number of mutated patients divided by total cases in each group.

Table 2: Univariate and multivariate analyses of prognostic factors for overall survival in AML patients

\begin{tabular}{lcccc}
\hline & Univariate analysis & \multirow{2}{*}{$\boldsymbol{P}$ value } & Multivariate analysis & \multirow{2}{*}{$\boldsymbol{P}$ value } \\
\cline { 2 - 2 } & Hazard ratio (95\% CI) & & Hazard ratio (95\% CI) & \\
\hline WBC & $2.494(1.809-3.439)$ & $<0.001$ & $1.758(1.1345-2.726)$ & 0.012 \\
age & $3.043(2.211-4.189)$ & $<0.001$ & $1.842(1.186-2.860)$ & 0.007 \\
Karyotypic classifications & $2.033(1.685-2.453)$ & $<0.001$ & $1.660(1.235-2.232)$ & 0.001 \\
Chemerin expression(low/ & $1.634(0.978-2.725)$ & 0.060 & $0.515(0.288-0.921)$ & 0.025 \\
high) & $2.920(1.348-6.326)$ & 0.007 & $3.063(1.173-7.994)$ & 0.022 \\
U2AF1 mutation & $0.875(0.472-1.621)$ & 0.671 & - & - \\
FLT3-ITD mutation & $1.046(0.578-1.894)$ & 0.882 & - & - \\
NPM1 mutation & $1.234(0.725-2.130)$ & 0.429 & - & - \\
CEBPA mutation & $0.755(0.309-1.845)$ & 0.538 & - & - \\
c-KIT mutation & $1.411(0.690-2.888)$ & 0.346 & - & - \\
N/K- $R A S$ mutation & $0.632(0.156-2.559)$ & 0.520 & - & - \\
$I D H 1 / 2$ mutation & $1.341(0.681-2.640)$ & 0.395 & - \\
DNMT3A mutation & & & - & - \\
\hline
\end{tabular}

analysis, the parameters associated with age $(\geq 60 /<60 \mathrm{y})$, WBC $\left(\geq 30 /<30 \times 10^{9} / \mathrm{L}\right)$, karyotype classifications (favorable/intermediate/poor), ten gene mutations (mutant/ wild-type), and chemerin expression (high/low) with $\mathrm{P}<0.20$ in univariate analysis, also identified that chemerin over-expression was an independent favorable prognostic factor in AML patients (Table 2).

\section{DISCUSSION}

Chemerin, a novel member of adipokines, is known to be involved in regulating adipogenesis and lipid metabolism, cell proliferation and migration, inflammation and leukocyte trafficking, endothelial angiogenesis and MMP production [7, 20, 21]. Recently, dysregulated expression of chemerin has been observed in numerous solid cancers including hepatocellular carcinoma [13, 22], skin squamous cell carcinoma [14], melanoma [15] and adrenocortical carcinoma [23]. These results suggest that chemerin expression may be tumor-specific in the process of tumorigenesis. However, the expression levels and functions of chemerin in AML have been little known. Our study for the first time reported about chemerin expression and its clinical significance in patients with AML.

In this study, we investigated the expression pattern of chemerin and further analyzed the clinical significance of chemerin expression in de novo AML patients. We provided evidence that chemerin was significantly lowexpressed in AML patients compared with the controls. In addition, we investigated by ROC curve analysis, high chemerin expression was a valuable biomarker for discriminating AML from healthy controls. High chemerin expression was observed in $21.5 \%$ of AML patients if the cut-off value 0.0826 was used according to ROC curve 
at the sensitivity of $79 \%$ and specificity of $54 \%$. It was shown that chemerin expression may serve as a potential biomarker to distinguish AML patients from normal controls.

Furthermore, our study found that high chemerin expression in whole cohort AML was significantly associated with favorable overall survival. We also demonstrated that the expression of chemerin was an independent prognostic factor for overall survival in de novo AML patients according to multivariate analyses. Interestingly, there was a trend of high chemerin expression toward the higher $\mathrm{CR}$ rate, which might be due to the small size of patients with $\mathrm{CR}$ in our cohort.
These results indicated that the chemerin expression levels was a valuable predictor for the assessment of therapeutic efficacy and status, and might serve as a standard for the therapeutic evaluation in AML.

Chemerin is a chemoattractant for macrophages, NK cells, and dendritic cells that induces cell migration $[24,25]$. The chemoattractant effect occurs via the $G$ protein-coupled receptor (GPCR) ChemR23, as well as $\mathrm{GPR} 1$, and chemokine $(\mathrm{C}-\mathrm{C}$ motif) receptor-like 2 (CCRL2) [8, 11]. The chemokine $\mathrm{C}-\mathrm{C}$ motif receptorlike 2 (CCRL2) expression has been shown on almost all human hematopoietic cells [26]. Previous reports have demonstrated that the chemerin receptor CCRL2

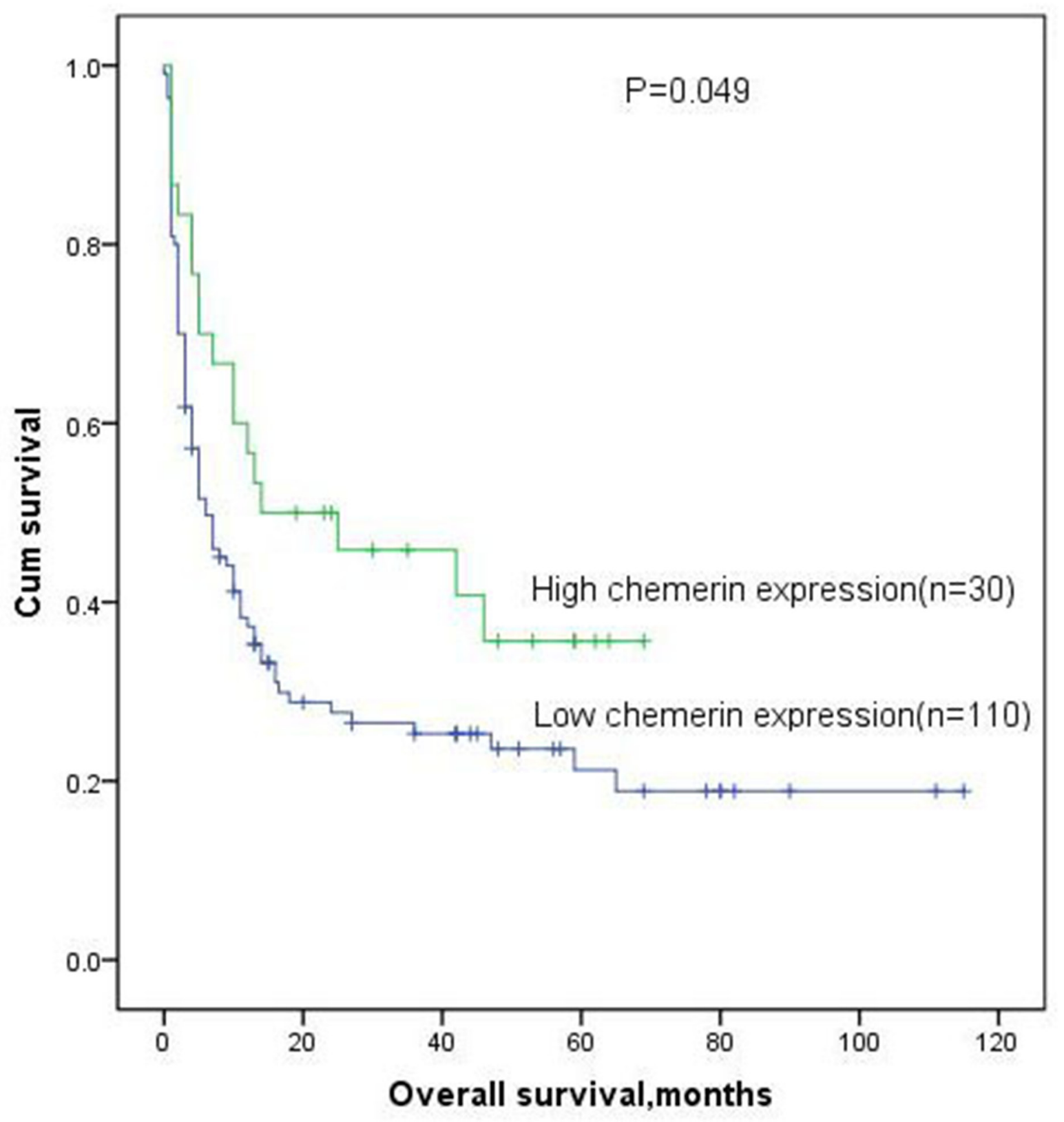

Figure 3: Overall survival analysis of AML patients. 
upregulation contributes to glioblastoma cell migration [27], cutaneous squamous cell carcinoma [28], and acute myeloid leukemia [29]. Moreover, to identify the potential roles of Chemerin/CCRL2 axis as a novel therapeutic target and biomarker need further investigations. In gastric carcinomas. Overexpression of chemerin was correlated with advanced clinical stage and enhanced invasiveness of gastric cancer cells. Chemerin was also shown to activate the phosphorylation of p38 and ERK1/2 MAPKs in gastric cancer [18]. Another study showed that Chemerin, depending on the cell type and the receptor expression can activate different subtypes of MAPK (mitogen-activated protein kinase) pathway [28]. Whether chemerin is influence the development of acute myeloid leukemia by activating the MAPK, we need to be further identified. Y LiuChittenden et al. indicated that chemerin was lowexpressed in adrenocortical carcinoma compared with normal and benign adrenocortical tissues, which was due to epigenetic $\mathrm{CpG}$ hypermethylation [23]. It may provide the possibility that $\mathrm{CpG}$ hypermethylation is causing chemerin downregulation in AML.

In conclusion, We provide the first expression analysis of chemerin in AML, decreased chemerin expression is negatively correlated with clinical outcome in patients with de novo AML. The chemerin expression was found to be an independent predictive marker in patients with AML. Future experiments will show whether chemerin are potential novel therapeutic targets in AML.

\section{MATERIALS AND METHODS}

\section{Patients and specimens}

A total of 149 patients who underwent primary and curative for de novo AML between 2005 and 2014 at the Affiliated People' Hospital of Jiangsu University were voted as the study population. Bone marrow samples were collected from 35 healthy donors. The diagnosis and classifications were made according to the FrenchAmerica-British (FAB) classification and World Health Organization (WHO) criteria [30,31]. Treatment protocol was described as reported previously [32]. Patients with major clinical parameters, including age, gender, karyotype classification, kayotype, and gene mutation are listed in Table 1.

All patients provided written informed consent. The use of clinical specimens in this study was approved by the Ethic Committee of Affiliated People' Hospital of Jiangsu University.

\section{RNA isolation and reverse transcription}

The bone marrow mononuclear cells (BMNCs) of AML patients at initial diagnosis and healthy donors were concentrated by Ficoll-Hypaque gradient. Total
RNA is extracted through the Trizol reagent (Invitrogen, Carlsbad, CA, USA) according to the manufacturer's instructions. 200 uints of MMLV reverse transcriptase (MBI Fermentas, Hanover, USA) containing $2 \mu \mathrm{g}$ of total RNA, $10 \mathrm{mM}$ of dNTPs, $10 \mu \mathrm{M}$ of random hexamer and 80 units of RNAs in were used for reverse transcription on iCycler Thermal Cycler (Eppendorf, Hamburg, Germany) to synthesize cDNA. The system of reverse transcription was incubated for 10 minutes at $25^{\circ} \mathrm{C}$, for 60 minutes at $42^{\circ} \mathrm{C}$, and then stored at $-20^{\circ} \mathrm{C}$.

\section{Real-time quantitative PCR}

Real-time quantitative PCR (RQ-PCR) analysis was carried out on a 7500 Thermocycler (Applied Biosystems, CA, USA). RQ-PCR for the final reaction volume of $20 \mu \mathrm{L}$ for each sample consisted of $20 \mathrm{ng}$ cDNA, $0.8 \mu \mathrm{M}$ primer, $10 \mu \mathrm{M}$ AceQ qPCR SYBR Green Master Mix (Vazyme Biotech Co., Piscataway, NJ, USA) and $0.4 \mu \mathrm{M}$ ROX Reference Dye 2 (Invitrogen). The PCR conditions were as following: $95^{\circ} \mathrm{C}$ for 5 minutes for initial denaturation, followed by 45 cycles at $95^{\circ} \mathrm{C}$ for 10 seconds for denaturation, $62^{\circ} \mathrm{C}$ for 30 seconds for annealing, and $72^{\circ} \mathrm{C}$ for 30 seconds for extension, and $80^{\circ} \mathrm{C}$ for 32 seconds to collect fluorescence, finally followed by $95^{\circ} \mathrm{C}$ for $15 \mathrm{~s}, 60$ ${ }^{\circ} \mathrm{C}$ for $60 \mathrm{~s}$. Positive and negative controls were included in each assay. Relative to chemerin expression levels were calculated according to the following formula: $\mathrm{N}_{\text {chemerin }}=$ $\left(\mathrm{E}_{\text {chemerin }}\right) \Delta \mathrm{CT}$ chemerinl(control-sample) $\div\left(\mathrm{E}_{\mathrm{ABL}}\right)^{\Delta \mathrm{CT} \text { ABL (control-sample) }}$ $\times 1000 \%$. The parameter efficiency $(\mathrm{E})$ derived from the formula $\mathrm{E}=10^{(-1 / \mathrm{slope})}$ (the slope referred to $\mathrm{CT}$ versus cDNA concentration plot).

\section{Gene mutation detection}

IDH1/IDH2, NPM1 and DNMT3A mutations were detected according to the literatures reported previously [33-36]. Using PCR and high-resolution melting analysis (HRMA) to detect the C-KIT and U2AF1 mutations. All positive samples were confirmed by direct DNA sequencing. C/EBPA and FLT3 internal tandem duplication (ITD) were detected by DNA sequencing.

\section{Statistical analysis}

Statistical analysis was performed using IBM SPSS Statistics (SPSS, Chicago, IL, version 20.0). Comparing the difference of qualitative data between patients groups were analyzed with the Chi-square test and Fisher's exact test. For these comparison analyses between the different study groups, Kruskal-Wallis and Mann-Whitney U test were applied. Receiver operating characteristic (ROC) curve and area under the ROC curve (AUC) were calculated to determine the diagnostic accuracy of chemerin expression in distinguishing AML patients from normal controls. Kaplan-Meier and Multivariate analysis were performed to identify factors associated 
with chemerin expression on survival respectively. All the analyses, $\mathrm{P}<0.05$ was considered statistically significant.

\section{ACKNOWLEDGMENTS AND FUNDING}

This study was supported by National Natural Science foundation of China (81172592, 81270630), Science and Technology Special Project in Clinical Medicine of Jiangsu Province (BL2012056), 333 Project of Jiangsu Province (BRA2011085).

\section{CONFLICTS OF INTEREST}

The authors declare no conflicts of interest.

\section{REFERENCES}

1. Estey E, Döhner H. Acute myeloid leukaemia. Lancet. 2006; 368:1894-907.

2. Haferlach T. Molecular genetic pathways as therapeutic targets in acute myeloid leukemia. Hematology Am Soc Hematol Educ Program. 2008:400-11.

3. Look AT. Oncogenic transcription factors in the human acute leukemias. Science. 1997; 278:1059-64.

4. Krug U, Ganser A, Koeffler HP. Tumor suppressor genes in normal and malignant hematopoiesis. Oncogene. 2002; 21:3475-95.

5. Fernandez-Pol S, Ma L, Ohgami RS, Arber DA. Immunohistochemistry for $\mathrm{p} 53$ is a useful tool to identify cases of acute myeloid leukemia with myelodysplasiarelated changes that are TP53 mutated, have complex karyotype, and have poor prognosis. Mod Pathol. 2017; 30:382-92.

6. Nagpal S, Patel S, Jacobe H, DiSepio D, Ghosn C, Malhotra M, Teng M, Duvic M, Chandraratna RA. Tazaroteneinduced gene 2 (TIG2), a novel retinoid-responsive gene in skin. J Invest Dermatol. 1997; 109:91-95.

7. Bondue B, Wittamer V, Parmentier M. Chemerin and its receptors in leukocyte trafficking, inflammation and metabolism. Cytokine Growth Factor Rev. 2011; 22:331-38.

8. Zabel BA, Nakae S, Zúñiga L, Kim JY, Ohyama T, Alt C, Pan J, Suto H, Soler D, Allen SJ, Handel TM, Song $\mathrm{CH}$, Galli SJ, Butcher EC. Mast cell-expressed orphan receptor CCRL2 binds chemerin and is required for optimal induction of IgE-mediated passive cutaneous anaphylaxis. J Exp Med. 2008; 205:2207-20.

9. Vermi W, Riboldi E, Wittamer V, Gentili F, Luini W, Marrelli S, Vecchi A, Franssen JD, Communi D, Massardi L, Sironi M, Mantovani A, Parmentier M, et al. Role of ChemR23 in directing the migration of myeloid and plasmacytoid dendritic cells to lymphoid organs and inflamed skin. J Exp Med. 2005; 201:509-15.
10. Wittamer V, Bondue B, Guillabert A, Vassart G, Parmentier M, Communi D. Neutrophil-mediated maturation of chemerin: a link between innate and adaptive immunity. J Immunol. 2005; 175:487-93.

11. Barnea G, Strapps W, Herrada G, Berman Y, Ong J, Kloss $\mathrm{B}$, Axel R, Lee KJ. The genetic design of signaling cascades to record receptor activation. Proc Natl Acad Sci USA. 2008; 105:64-69.

12. Salama FE, Anass QA, Abdelrahman AA, Saeed EB. Chemerin: A biomarker for cardiovascular disease in diabetic chronic kidney disease patients. Saudi J Kidney Dis Transpl. 2016; 27:977-84.

13. Lin W, Chen YL, Jiang L, Chen JK. Reduced expression of chemerin is associated with a poor prognosis and a lowed infiltration of both dendritic cells and natural killer cells in human hepatocellular carcinoma. Clin Lab. 2011; 57:879-85.

14. Zheng Y, Luo S, Wang G, Peng Z, Zeng W, Tan S, Xi Y, Fan J. Downregulation of tazarotene induced gene-2 (TIG2) in skin squamous cell carcinoma. Eur J Dermatol. 2008; 18:638-41.

15. Pachynski RK, Zabel BA, Kohrt HE, Tejeda NM, Monnier J, Swanson CD, Holzer AK, Gentles AJ, Sperinde GV, Edalati A, Hadeiba HA, Alizadeh AA, Butcher EC. The chemoattractant chemerin suppresses melanoma by recruiting natural killer cell antitumor defenses. J Exp Med. 2012; 209:1427-35.

16. Ahn KY, Lee MK, Kim DI, Park J, Min J, In Yang H, Lee J, Oh M, An J, Lee JW, Chu SH, Meyerhardt JA, Kim NK, Jeon JY. Cardiopulmonary fitness, adiponectin, chemerin associated fasting insulin level in colorectal cancer patients. Support Care Cancer. 2016; 24:2927-35.

17. Wang N, Wang QJ, Feng YY, Shang W, Cai M. Overexpression of chemerin was associated with tumor angiogenesis and poor clinical outcome in squamous cell carcinoma of the oral tongue. Clin Oral Investig. 2014; 18:997-1004.

18. Wang C, Wu WK, Liu X, To KF, Chen GG, Yu J, Ng EK. Increased serum chemerin level promotes cellular invasiveness in gastric cancer: a clinical and experimental study. Peptides. 2014; 51:131-38.

19. Yamaguchi Y, Du XY, Zhao L, Morser J, Leung LL. Proteolytic cleavage of chemerin protein is necessary for activation to the active form, Chem157S, which functions as a signaling molecule in glioblastoma. J Biol Chem. 2011; 286:39510-19.

20. Roh SG, Song SH, Choi KC, Katoh K, Wittamer V, Parmentier M, Sasaki S. Chemerin — a new adipokine that modulates adipogenesis via its own receptor. Biochem Biophys Res Commun. 2007; 362:1013-18.

21. Kaur J, Adya R, Tan BK, Chen J, Randeva HS. Identification of chemerin receptor (ChemR23) in human endothelial cells: chemerin-induced endothelial angiogenesis. Biochem Biophys Res Commun. 2010; 391:1762-68. 
22. Lin Y, Yang X, Liu W, Li B, Yin W, Shi Y, He R. Chemerin has a protective role in hepatocellular carcinoma by inhibiting the expression of IL-6 and GM-CSF and MDSC accumulation. Oncogene. 2017; 36:3599-608. https://doi. org/10.1038/onc.2016.516.

23. Liu-Chittenden Y, Jain M, Gaskins K, Wang S, Merino MJ, Kotian S, Kumar Gara S, Davis S, Zhang L, Kebebew E. RARRES2 functions as a tumor suppressor by promoting $\beta$-catenin phosphorylation/degradation and inhibiting p38 phosphorylation in adrenocortical carcinoma. Oncogene. 2017; 36:3541-52.

24. Kumar JD, Holmberg C, Kandola S, Steele I, Hegyi P, Tiszlavicz L, Jenkins R, Beynon RJ, Peeney D, Giger OT, Alqahtani A, Wang TC, Charvat TT, et al. Increased expression of chemerin in squamous esophageal cancer myofibroblasts and role in recruitment of mesenchymal stromal cells. PLoS One. 2014; 9:e104877.

25. Yoshimura T, Oppenheim JJ. Chemerin reveals its chimeric nature. J Exp Med. 2008; 205:2187-90.

26. Yoshimura T, Oppenheim JJ. Chemokine-like receptor 1 (CMKLR1) and chemokine (C-C motif) receptor-like 2 (CCRL2); two multifunctional receptors with unusual properties. Exp Cell Res. 2011; 317:674-84.

27. Yin F, Xu Z, Wang Z, Yao H, Shen Z, Yu F, Tang Y, Fu D, Lin S, Lu G, Kung HF, Poon WS, Huang Y, Lin MC. Elevated chemokine CC-motif receptor-like 2 (CCRL2) promotes cell migration and invasion in glioblastoma. Biochem Biophys Res Commun. 2012; 429:168-72.

28. Farsam V, Basu A, Gatzka M, Treiber N, Schneider LA, Mulaw MA, Lucas T, Kochanek S, Dummer R, Levesque MP, Wlaschek M, Scharffetter-Kochanek K. Senescent fibroblast-derived Chemerin promotes squamous cell carcinoma migration. Oncotarget. 2016; 7:83554-69. https://doi.org/10.18632/oncotarget.13446.

29. Maiga A, Lemieux S, Pabst C, Lavallée VP, Bouvier M, Sauvageau G, Hébert J. Transcriptome analysis of G protein-coupled receptors in distinct genetic subgroups of acute myeloid leukemia: identification of potential diseasespecific targets. Blood Cancer J. 2016; 6:e431.

30. Bennett JM, Catovsky D, Daniel MT, Flandrin G, Galton DA, Gralnick HR, Sultan C. Proposed revised criteria for the classification of acute myeloid leukemia. A report of the French-American-British Cooperative Group. Ann Intern Med. 1985; 103:620-25.

31. Campo E, Swerdlow SH, Harris NL, Pileri S, Stein H, Jaffe ES. The 2008 WHO classification of lymphoid neoplasms and beyond: evolving concepts and practical applications. Blood. 2011; 117:5019-32.

32. Li Y, Lin J, Yang J, Qian J, Qian W, Yao DM, Deng ZQ, Liu Q, Chen XX, Xie D, An C, Tang CY. Overexpressed let-7a-3 is associated with poor outcome in acute myeloid leukemia. Leuk Res. 2013; 37:1642-47.

33. Lin J, Yao DM, Qian J, Chen Q, Qian W, Li Y, Yang J, Wang CZ, Chai HY, Qian Z, Xiao GF, Xu WR. Recurrent DNMT3A R882 mutations in Chinese patients with acute myeloid leukemia and myelodysplastic syndrome. PLoS One. 2011; 6:e26906.

34. Lin J, Yao DM, Qian J, Chen Q, Qian W, Li Y, Yang J, Wang CZ, Chai HY, Qian Z, Xiao GF, Xu WR. IDH1 and IDH2 mutation analysis in Chinese patients with acute myeloid leukemia and myelodysplastic syndrome. Ann Hematol. 2012; 91:519-25.

35. Yang X, Qian J, Sun A, Lin J, Xiao G, Yin J, Chen S, Wu D. RAS mutation analysis in a large cohort of Chinese patients with acute myeloid leukemia. Clin Biochem. 2013; 46:579-83.

36. Qian J, Yao DM, Lin J, Qian W, Wang CZ, Chai HY, Yang J, Li Y, Deng ZQ, Ma JC, Chen XX. U2AF1 mutations in Chinese patients with acute myeloid leukemia and myelodysplastic syndrome. PLoS One. 2012; 7:e45760. 